\title{
Análise da Rede de Postos de Chuva na Previsão em Tempo Real na Bacia do Rio Uruguai
}

\author{
Ivanilto Andreolli, Walter Collischonn, Carlos Eduardo Morelli Tucci \\ Instituto de Pesquisas Hidráulicas, IPH/UFRGS \\ ivanilto_andreolli@yahoo.com.br, cllschnn@vortex.ufrgs.br,351522@vortex.ufrgs.br
}

Recebido: 30/06/04 - revisado: 21/10/05 - aceito: 27/03/06

\begin{abstract}
RESUMO
A previsão hidrológica em tempo real busca prever a vazão ou níveis de água em tempos futuros, utilizando variáveis como vazões observadas à montante e jusante do rio e chuvas observadas ou previstas. As chuvas observadas são obtidas, em geral, por uma rede de postos telemétricos distribuídos na bacia e são fundamentais para previsões em tempos futuros inferiores ao tempo de concentração da bacia. A análise da distribuição de postos de chuva na bacia, por sua vez, pode contribuir para o dimensionamento de redes telemétricas e trazer benefícios significativos para previsão em tempo real. Este artigo apresenta uma metodologia para avaliar o desempenho de uma rede de postos de chuva com base na previsão em tempo real. A análise foi feita na Bacia do rio Uruguai até o reservatório de Machadinho com área de drenagem de $32.000 \mathrm{~km}^{2}$. Mais de dois anos de previsão contínua foram avaliados considerando diversos cenários de distribuicãa dos postos de chuva na bacia. Os resultados mostraram que uma rede bem distribuída na bacia pode trazer benefícios significativos em termos de previsão de vazão nesta bacia.
\end{abstract}

Palavras-chave: avaliação de rede telemétrica; previsão em tempo real; Rio Uruguai.

\section{INTRODUCÃ̃O}

A previsão de vazão de curto prazo, também denominada de previsão em tempo real, é utilizada para estimar a vazão ou nível numa seção com antecedência de horas ou poucos dias, acompanhando a ocorrência do fenômeno que está para atingir ou que já atingiu a bacia. A previsão de longo prazo é a previsão com alguns meses de antecipação. A predição é a estimativa, geralmente estatística, da probabilidade de ocorrência de vazões num determinado local, como, por exemplo: a probabilidade de inundação numa seção de um rio, a probabilidade de períodos úmidos e secos, entre outros (Andreolli, et al., 2003; Tucci et al., 2003; Lettenmaier e Wood, 1993).

A previsão de curto prazo, ou previsão em tempo real, pode ser utilizada, entre outras aplicações, para alerta de inundação em áreas ribeirinhas e para melhorar a operação de sistemas hidrelétricos. Essa previsão pode ser realizada com base em postos de vazão e com base na precipitação e vazão. Essas previsões dependem do conhecimento do estado do sistema (umidade do solo, vazões observa- das a montante e jusante do rio, e, ou das chuvas recentes, ou previstas). $\mathrm{O}$ uso de determinado modelo de previsão fica condicionado a essas informações, as quais são obtidas através de modelos de previsão de chuva e da rede hidrológica que pode estar associada à telemetria (transmissão em tempo real).

Operacionalmente, na previsão em tempo real, as informações de chuva e de níveis necessitam de uma rede telemétrica para serem transmitidos em tempo real ao centro de previsão gerando custos adicionais, fator que limita as previsões em países em desenvolvimento. A rede telemétrica é importante para atualização do sistema (Tucci e Clarke, 1980; Wood e Connell, 1985; O`Connell e Clarke, 1981) e para a inserção de novas informações de chuva e vazão no modelo de previsão, ao longo do tempo (Andreolli, 2003).

A distribuição espacial dos postos da rede telemétrica na bacia, bem como a densidade de postos influencia no desempenho da previsão em tempo real, porque a representatividade temporal e espacial da chuva e da própria vazão depende dos pontos de observação da chuva e vazão. Uma rede telemétrica densa, bem distribuída, diminui as in- 
certezas dos dados de chuva e vazão observados e pode trazer benefícios na previsão em tempo real (Clarke e Dias, 2002).

Considerando que os recursos são limitados, mesmo para países desenvolvidos, se torna importante para o gestor do sistema de operação do reservatório a resposta das seguintes questões. Se estiverem disponíveis recursos para instalação de mais $n$ postos de chuva com telemetria em quais regiões da bacia esses postos devem ser instalados para obter maior ganho na previsão? Esse ganho é realmente significativo?

As informações quantitativas do desempenho das previsões em função do número de pluviógrafos, ou de sua distribuição na bacia, é importante; devido às probabilidades altas de ocorrerem falhas na rede; para dimensionamento de uma rede próxima à ideal e também para apontar possíveis regiões de maior importância de geração de escoamento a serem monitoradas.

Estas questões foram estudadas para uma bacia (Rio Uruguai em Machadinho) como estudo de caso. Foram feitas previsões no período de setembro de 2001 a julho de 2003 no reservatório de Machadinho para alguns cenários e as previsões foram comparadas com as vazões observadas.

\section{METODOLOGIA}

Os estudos realizados basearam-se no seguinte: (a) existe uma rede de postos da rede telemétrica; (b) existe uma rede complementar que não faz para da rede telemétrica, mas permite estimativa da precipitação na bacia; (c) as duas redes podem permitir a estimativa da precipitação de um evento ocorrido, mas apenas a rede telemétrica pode ser utilizada em tempo real. Considerando que a rede telemétrica pode ser ampliada pelos postos existentes foram estudados os seguintes cenários:

1) uso apenas dos postos da rede telemétrica e, portanto retirada de todos os outros postos disponíveis;

2) uso seletivo de postos por sub-região da bacia mantendo todos os postos disponíveis e retirando apenas por sub-região (retirada da rede convencional e telemétrica);

3) o mesmo procedimento do cenário anterior, mas com retirada semi-aleatória de postos que não constituem a rede telemétrica. Este estudo de cenários é uma análise com- parativa relativa da capacidade de previsão de um modelo hidrológico, considerando algumas alternativas de postos de precipitação durante a previsão. Deve-se considerar também que o modelo foi ajustado utilizando-se da melhor rede, portanto, não se está incorporando o erro de ajuste pela falta de dados, mas apenas da previsão.

A retirada dos postos que não fazem parte da rede telemétrica é importante, porque esses postos não podem ser utilizados para previsão em tempo real operacionalmente e este cenário representa as previsões possíveis de serem feitas atualmente no reservatório de Machadinho. A retirada de postos por região é importante para avaliar o desempenho na previsão quando um novo posto é inserido em determinada região da bacia. A retirada semialeatória é importante para avaliar a rede telemétrica e o desempenho na previsão quando ocorrerem falhas em um ou mais postos na bacia.

Para avaliação dos cenários citados foi utilizado um modelo hidrológico distribuído por células, desenvolvido para aplicações em grandes bacias (Collischonn, 2001). Este modelo foi calibrado em estudos anteriores (Collischonn, 2001; Tucci, et al., 2003). O intervalo de tempo do modelo é 1 hora, ou seja, previsões de hora em hora são gerados. A avaliação do cenário 1 (retirada de todos os postos convencionais) e cenário 2 (retirada de postos por região - postos convencionais e telemétricos) foi feita considerando previsões em tempo real de 0 a 12 horas de antecedências. Já para avaliação do cenário 3 (retirada de postos semi-aleatória - postos convencionais), apenas as previsões para a antecedência de 12 horas foram realizadas, considerando falhas semialeatórias nos pluviômetros existentes atualmente na bacia. O patamar de 12 horas representa aproximadamente o tempo de pico do hidrograma gerado em Machadinho. Este horizonte também representa, aproximadamente, o patamar superior de previsão aceitável de previsão com base na hipótese de chuva zero (Collischonn, et al., 2004; Andreolli, 2003; Tucci, et al., 2003).

O período considerado foi de 11/09/2001 a 29/07/2003, que é o período de dados disponíveis do conjunto de informações de precipitação e vazão para a bacia.

A divisão por regiões foi feita em 7 subbacias segundo a rede de drenagem principal e a forma da bacia. Foram retirados individualmente 8 postos de cada sub-bacia, ou em região próxima de tal forma a totalizar os 8 postos e, então, realizada a previsão contínua de 12 horas para Machadinho. Esta análise é importante para determinar qual região da bacia é mais importante para geração de esco- 
amento em determinada seção do rio, no caso, Machadinho e apontá-la para melhor monitoramento.

Nas retiradas semi-aleatórias adotou-se o seguinte critério: a bacia foi dividida em 6 faixas verticais (direção norte-sul); retirou-se aleatoriamente um posto convencional de cada faixa formando o primeiro conjunto de postos; repetiu-se o procedimento anterior resultando então em 12 postos e constituindo o segundo conjunto. A seqüência seguiu até a retirada total dos postos convencionais existentes (36 pluviômetros), resultado no sexto conjunto de postos. Para cada conjunto foi feita a previsão de vazão de 12 horas em Machadinho, resultando 6 simulações. Foi feito um total de 24 simulações. Para as demais simulações, totalizando as 24 simulações, consideraram-se os conjuntos já formados anteriormente, escolhendo-os de forma a não haver repetição da previsão. Para cada simulação (previsão) foi calculado o erro padrão na vazão e construída a curva "erro padrão versus número de postos utilizados".

A análise dos cenários foi feita com base em algumas estatísticas que são comumente utilizadas em previsões em tempo real. Utilizou-se a estatística RD (coeficiente de eficiência) dado pela equação 1 e também a estatística Ep (erro padrão na vazão) dado pela equação 2 .

O fator RD é um fator que envolve a comparação relativa entre dois modelos sendo o modelo alternativo aquele que considera a vazão futura igual à vazão atual (Kitanidis. e Bras, 1980). Este modelo é particularmente interessante para avaliar a eficiência da previsão em tempo real (Tucci, 1998). Valores negativos do coeficiente indicam que o modelo alternativo é melhor e valores positivos indicam que existe vantagem, na média, em utilizar o modelo de previsão proposto.

$\mathrm{RD}=1-\frac{\sum\left(\mathrm{Q}_{\mathrm{obs}}-\mathrm{Q}_{\mathrm{cal}}\right)^{2}}{\sum\left(\mathrm{Q}_{\mathrm{obs}}-\mathrm{Q}_{\mathrm{obs}}\left(\mathrm{t}_{0}\right)\right)^{2}}$

onde: RD, coeficiente de eficiência; $Q_{\text {obs }}$, vazão observada; $Q_{\text {cal }}$, vazão calculada; $Q_{\text {obs }}\left(t_{0}\right)$, vazão observada no instante inicial de previsão. Este coeficiente é um indicador importante da melhoria da previsão.
A medida que cresce em direção a 1, mostra aumento da precisão da previsão.

O erro padrão mede a dispersão das previsões em torno das observações.

$\mathrm{E}_{\mathrm{p}}=\left[\frac{1}{\mathrm{n}} \sum\left(\mathrm{Q}_{\mathrm{cal}}-\mathrm{Q}_{\mathrm{obs}}\right)^{2}\right]^{\frac{1}{2}}$

onde: Ep, erro padrão; n, número de observações.

\section{A BACIA DO RIO URUGUAI ATÉ MACHADINHO}

O rio Uruguai forma-se na região sul do Brasil, entre os Estados de Santa Catarina e do Rio Grande do Sul, a partir da confluência dos rios Canoas e Pelotas (conforme as figuras 1 e 3). A figura 1 mostra a localização da bacia do Uruguai em terras brasileiras onde também é destacada a área considerada neste estudo (seção do reservatório de Machadinho). Esta bacia possui área de drenagem de $32.000 \mathrm{~km}^{2}$. Apesar da grande área da bacia, o escoamento na região é bastante rápido devido às altas declividades dos rios e predominância de escoamento superficial, gerado pela fina camada de solo argiloso. A rapidez das cheias em Machadinho faz com que previsões do tipo vazão-vazão se deteriorem rapidamente e, dessa forma, justificam a necessidade da utilização de informações de chuva em tempo real na previsão.

As nascentes dos rios Canoas e Pelotas estão localizadas em uma região de campos e florestas, a uma altitude que chega a mais de $1.500 \mathrm{~m}$. O relevo da bacia é bastante pronunciado e os rios, especialmente o rio Pelotas, apresentam grande declividade. Atualmente, a confluência dos rios Pelotas e Canoas, que marca o início do rio Uruguai, está na região de remanso do reservatório de Machadinho. 


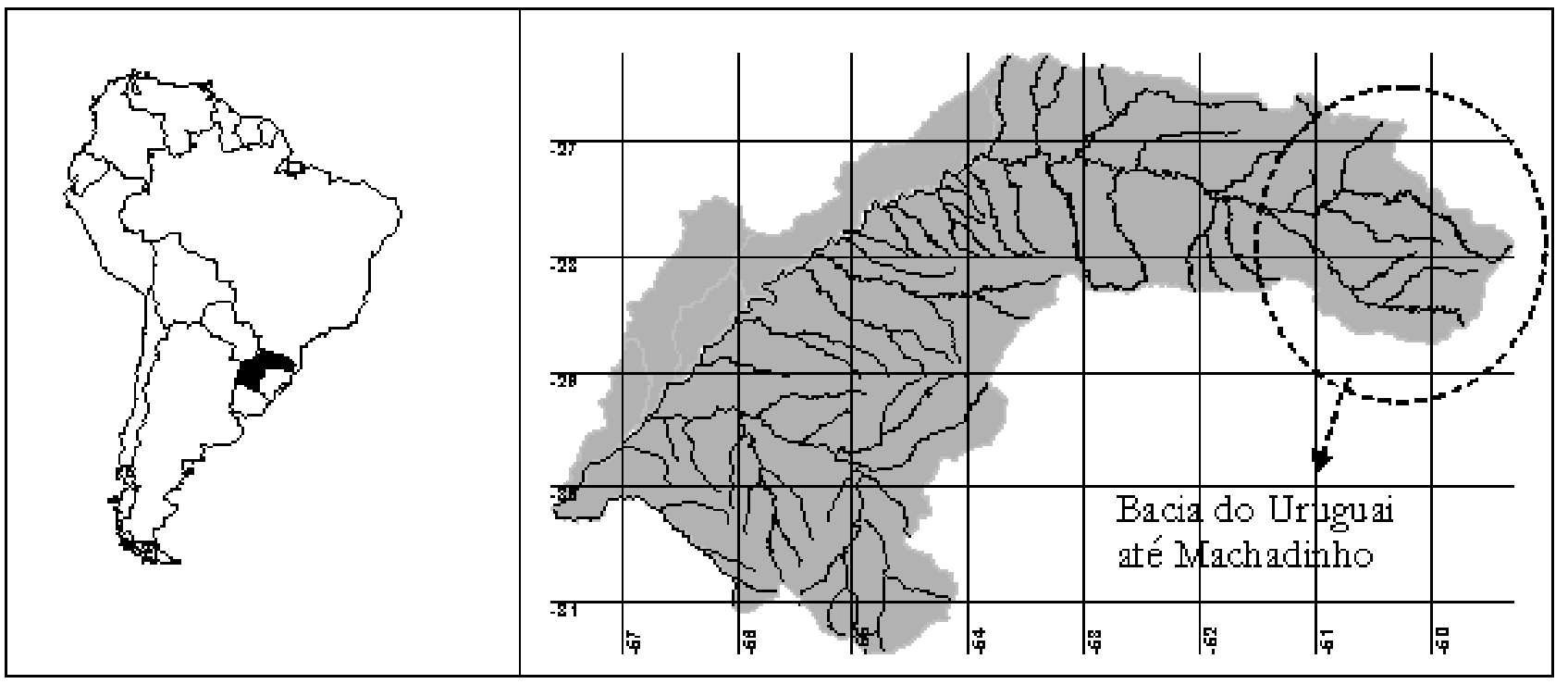

Figura 1 - Situação da bacia do Uruguai em território brasileiro: à esquerda a situação na América do Sul, à direita o destaque da bacia até Machadinho (área considerada neste estudo).

A bacia do rio Uruguai, à montante de Machadinho, está inteiramente localizada na região do derrame basáltico sul-brasileiro. Em geral, as rochas que formam o substrato desta região apresentam pouca porosidade e baixa capacidade de absorver e armazenar a água do solo. Os solos na bacia do rio Uruguai à montante de Machadinho contêm altos teores de argila, o que contribui para reduzir a capacidade de infiltração. Além disso, a camada de solo sobre o substrato rochoso nas regiões das encostas é relativamente fina, apresentando pouca capacidade de armazenamento. Assim, as características de geologia e solos da região contribuem para uma baixa capacidade de regularização natural de vazão na bacia, com grande predomínio do escoamento superficial em detrimento do escoamento subterrâneo.

Em conseqüência das características físicas da bacia, tais como relevo pronunciado, fortes declividades, solos relativamente argilosos, rasos e pouco permeáveis e substrato rochoso de basalto com baixa capacidade de armazenamento e regularização, as cheias no rio Uruguai ocorrem com muita rapidez apresentando baixa "memória" e a vazão do rio é altamente variável. Além disso, as cheias na bacia ocorrem com maior freqüência no inverno, porém podem ocorrer cheias em qualquer época do ano devido as condicionantes climáticas. A figura 2 apresenta a sazonalidade das vazões máximas para uma série de vazões de um posto próximo à seção de Machadinho. A série de dados é de 30 anos. O código e o nome do posto, pela numeração da Agência Na- cional de Águas - ANA, são, respectivamente, 72300000 e Passo Virgilho.

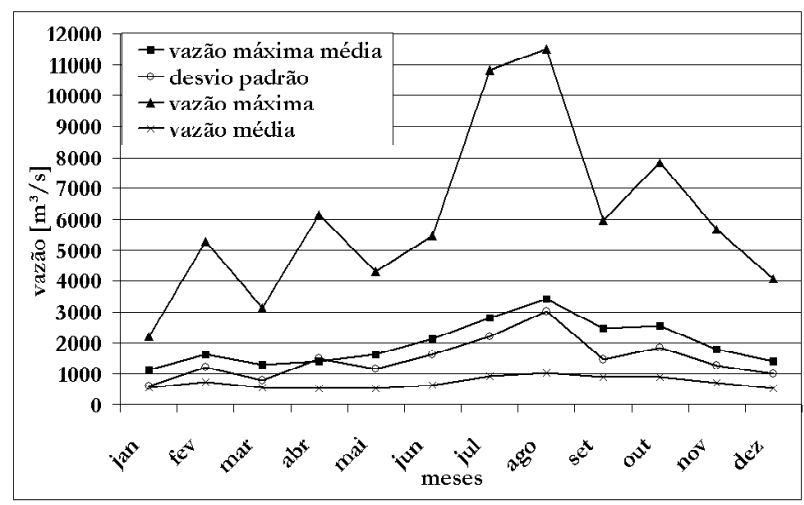

Figura 2 - Sazonalidade de vazões próximo a Machadinho, posto 72300000 .

Na figura 2 a curva superior apresenta as vazões máximas de cada mês da série de 30 anos (1971 - 2001). Essa curva mostra que apesar dos meses de dezembro a abril apresentarem vazões menores que nos meses de inverno, nesses meses também ocorrem eventos de cheia. Esse fato é muito importante, pois mostra a imprevisibilidade das cheias na bacia mostrando a importância de estudos de previsão em tempo real na bacia. Observando a curva das médias das máximas mensais da série de 30 anos novamente nota-se um crescimento de afluência de maio a agos- 
to, porém fica claro que ocorrem eventos chuvosos nos outros meses. A curva que apresenta o desvio padrão das máximas mensais ratifica a ocorrência de cheias em todos os períodos. Também na figura é apresentado a média das vazões mensais com objetivo de servir de base de comparação em magnitude das vazões máximas.

Os dados da rede telemétrica são armazenados e transmitidos em intervalos de 1 hora, o que é adequado para representar as rápidas variações de nível dos rios da região. Os linígrafos estão localizados no rio Canoas (Passo Caru) e rio Pelotas (Passo Socorro) conforme figura observa-se pela figura 3 . Além dos postos telemétricos de vazão também existem dados de postos convencionais, de leitura manual com leituras 2 vezes ao dia e dados de vazão em Machadinho de 4 em 4 horas gerados por balanço hídrico. A figura 3 apresenta a distribuição dos postos de chuva e a localização dos linígrafos.

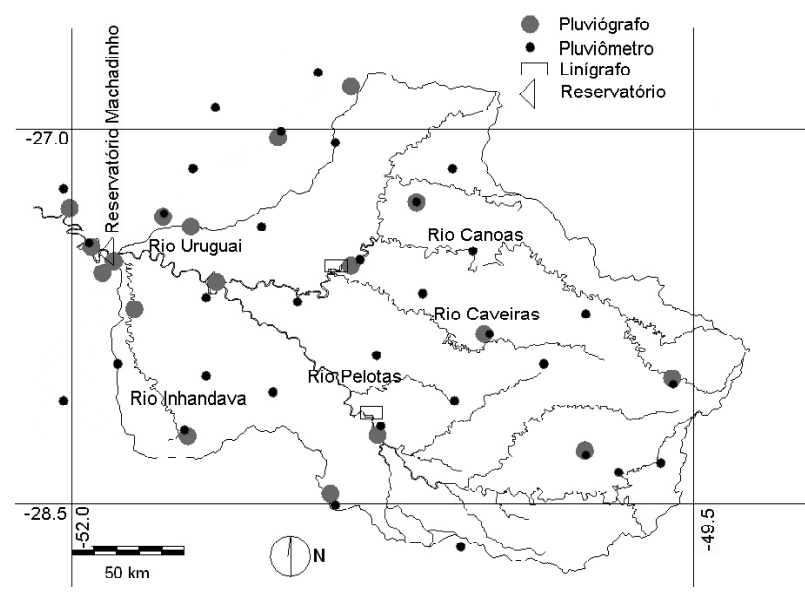

Figura 3 - Rede de postos de chuva e linígrafos na bacia do rio Uruguai até Machadinho.

\section{O MODELO HIDROLÓGICO}

O modelo hidrológico utilizado foi o modelo de grandes bacias (Collischonn, 2001). O modelo utiliza a discretização espacial em células quadradas. Nesta aplicação a área da bacia em estudo foi dividida em células quadradas e uniformes de $0,1 \times 0,1$ graus, o que corresponde a, aproximadamente, $10 \mathrm{x}$ $10 \mathrm{~km}$ nesta região. A figura 4 apresenta a bacia discretizada.

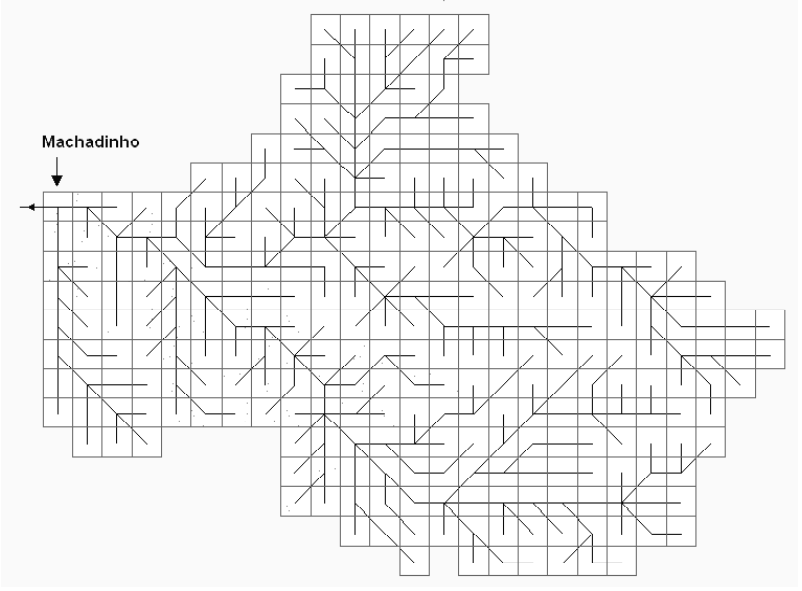

Figura 4 - Discretização da bacia em células quadradas.

O intervalo de tempo da previsão e calibração do modelo é variável e para esta aplicação o intervalo adotado foi de 1 hora coincidindo com o intervalo dos dados telemétricos de chuva.

O modelo foi calibrado em estudos anteriores (collischonn, 2001; Tucci, et al, 2003), sendo apresentados neste estudo apenas alguns resultados da calibração. A figura 5 apresenta os hidrogramas calculados e simulados para seção de Machadinho na estação de inverno de 2002 (estação chuvosa na região).

Na tabela 1 apresenta-se a síntese de duas funções objetivo utilizadas na calibração: o coeficiente NS - Nash Sutcliff (1970) obtido em Machadinho e nos postos Passo Caru e Passo do Socorro, e o erro de volume $(\Delta \mathrm{V})$ calculados, durante todo o período de calibração (set. 2001 a mar. 2003).

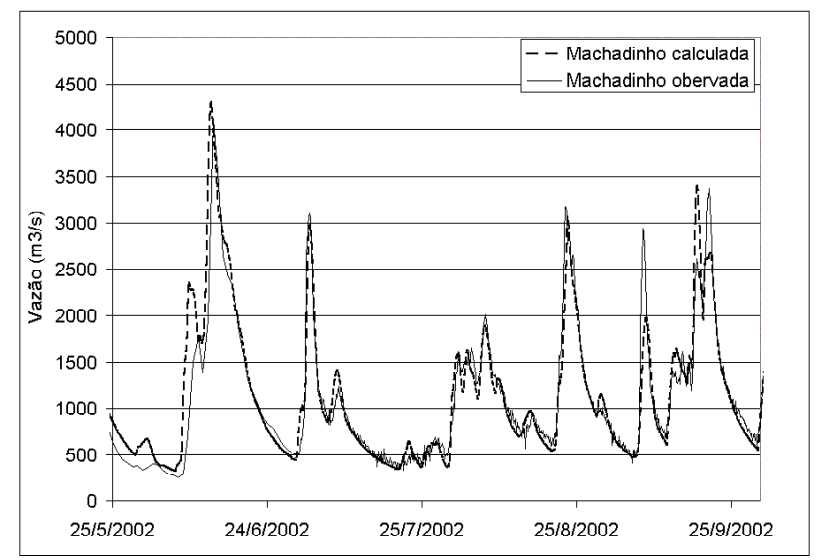

Figura 5 - Resultados de vazão calculada no rio Uruguai em Machadinho após a calibração (mai/2002 a set/2002). 
Tabela1 - Resultados das funções objetivo na calibração

\begin{tabular}{|l|c|c|c|}
\hline Função & $\begin{array}{l}\text { Passo do } \\
\text { Socorro }\end{array}$ & Passo Caru & Machadinho \\
\hline NS & 0,81 & 0,85 & 0,89 \\
\hline$\Delta \mathrm{V}[\%]$ & 9,4 & 8,3 & 3,2 \\
\hline
\end{tabular}

A análise dos hidrogramas da figura 5 mostra um excelente ajuste entre vazão observada e simulada em Machadinho. A síntese da simulação, dada pelas funções objetivo da tabela 1 também mostra os bons resultados obtidos.

\section{RESULTADOS}

Sub-áreas ou regiões e retirada dos postos convencionais

Na figura 6 é apresentada a sub-divisão definida para a bacia em sub-áreas representativas. Esta sub-divisão foi realizada com base na rede de drenagem principal considerando os principais rios formadores do rio Uruguai na seção de Machadinho.

A área em estudo foi dividida em sete subbacias, onde: Pelotas montante é a sub-bacia do rio Pelotas na região de cabeceira; Pelotas jusante é a sub-bacia do rio Pelotas na região mais à jusante; Canoas montante é a sub-bacia do rio Canoas na região de cabeceira; Canoas jusante é a sub-bacia do rio Canoas na região mais à jusante; Caveira é a subbacia do rio Caveira; Inhandava é a sub-bacia do rio Inhandava e Machadinho é a sub-bacia do rio Uruguai da confluência do rio Pelotas e Canoas até o reservatório de Machadinho exceto a bacia do Inhandava. No exutório da bacia "Canoas montante", está localizado o posto de vazão telemétrica (linígrafo) "Passo Caru". Já no exutório da bacia "Pelotas montante" está localizado o posto de vazão telemétrica "Passo Socorro". A figura 7 apresenta o coeficiente RD em função do horizonte de previsão para o cenário da retirada de postos em sub-bacias e também o cenário da retirada de todos os postos convencionais da bacia completa (RD sem pluviômetros).

$\mathrm{Na}$ legenda da figura 7, "RD completa" representa a curva do fator RD considerando a totalidade de postos e "RD sem pluviômetros" representa a curva RD desconsiderando todos os pluviômetros na bacia, "RD sem Canoas jusante" representa a curva $R D$ desconsiderando os postos na região do Canoas jusante. A analogia é válida para os demais nomes.

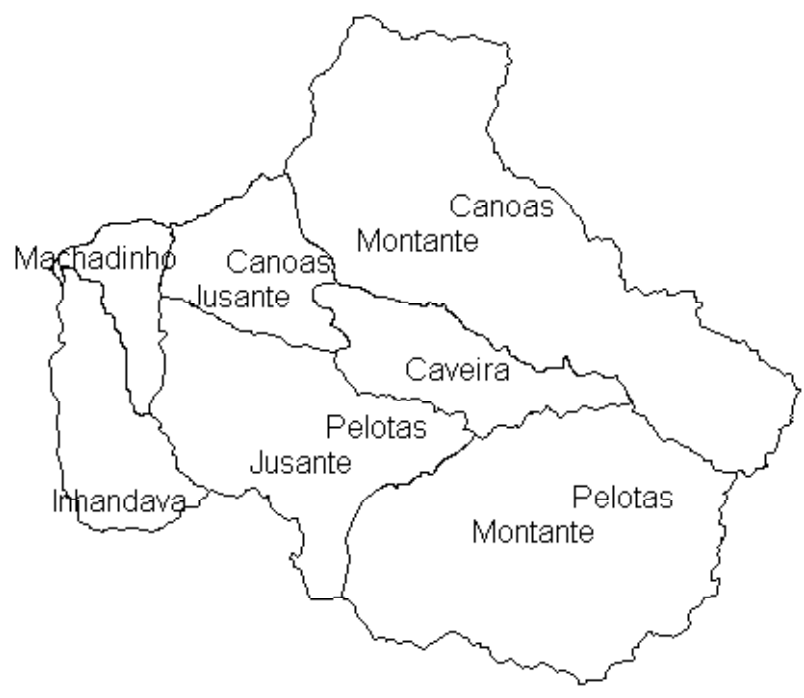

Figura 6 - Divisão da bacia em sub-bacias

A figura 8 apresenta um detalhe do feixe das seis curvas superiores da figura 7 .

O horizonte analisado vai de 0 horas a 12 horas de antecedência, porém, nota-se que o fator RD continua crescendo em 12 horas (derivada de primeira ordem positiva). Devido a grande quantidade de dados associados às dificuldades computacionais de processamento, é apresentado neste estudo uma análise até a antecedência de $12 \mathrm{~h}$. O fator RD é apresentado somente a partir da antecedência 4h em diante, porque abaixo desse horizonte o fator RD é negativo e o melhor dos modelos propostos é o de persistência.

Deve-se observar primeiramente que a retirada de todos os postos convencionais da bacia (pluviômetros) ocasiona grandes perdas de qualidade na previsão, representada pela curva, "RD sem pluviômetros”. Essa curva é importante, pois representa as previsões que poderiam ser feitas operacionalmente em Machadinho, haja vista que não é possível utilizar dados de pluviômetros nesta bacia para previsão em tempo real operacionalmente. Essa curva, quando comparada com as demais, mostra, em parte, a importância de uma rede densa postos na bacia. É importante notar que, casos esses postos (pluviômetros) fossem substituídos por pluviógrafos, provavelmente ter-se-ia um ganho superior em termos de previsão de vazão do que a ilustrada na figura 7. Isso porque a distribuição temporal da chuva estaria melhor caracterizada. 


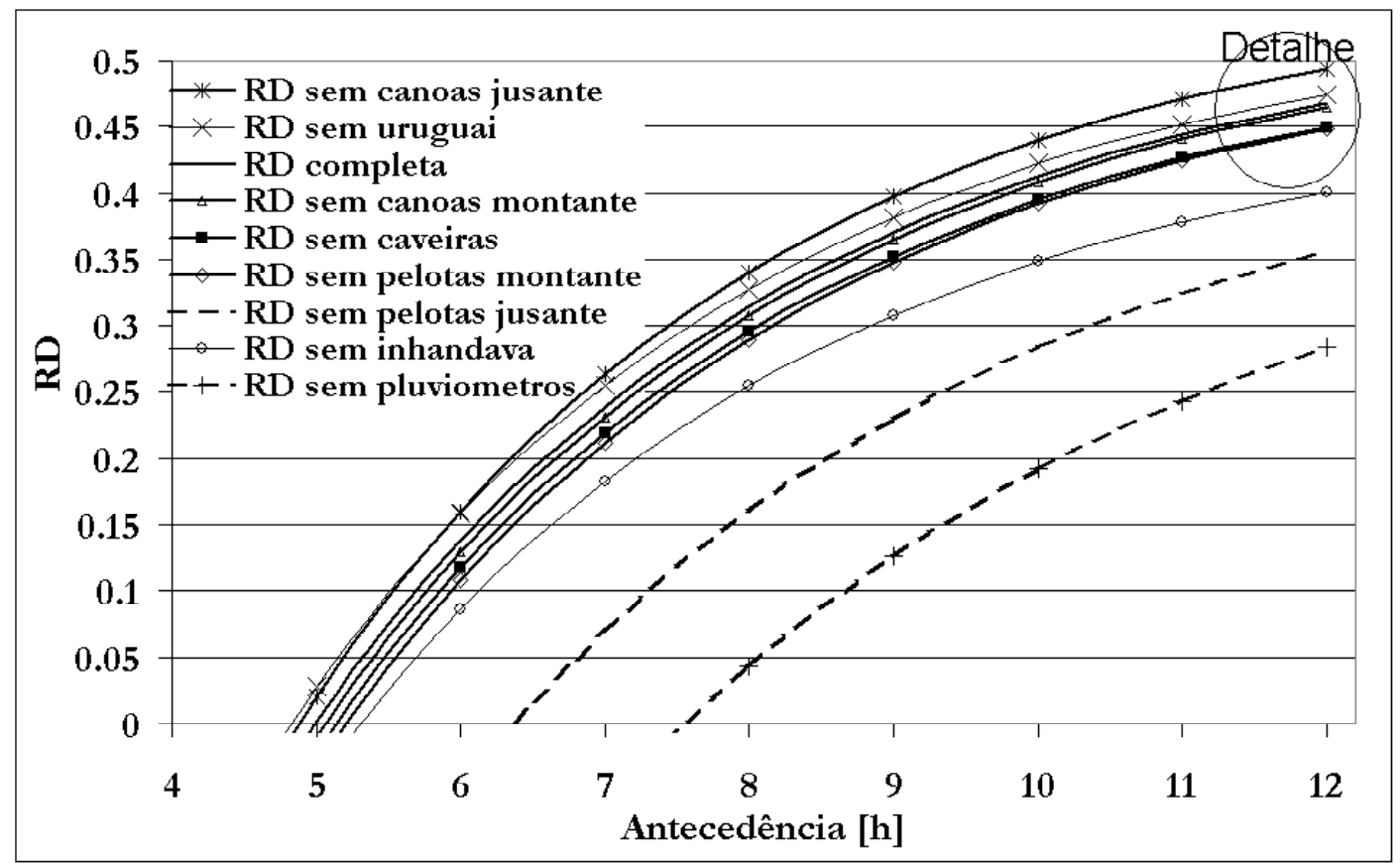

Figura 7 - Fator RD em função da antecedência para diversos cenários de previsão.

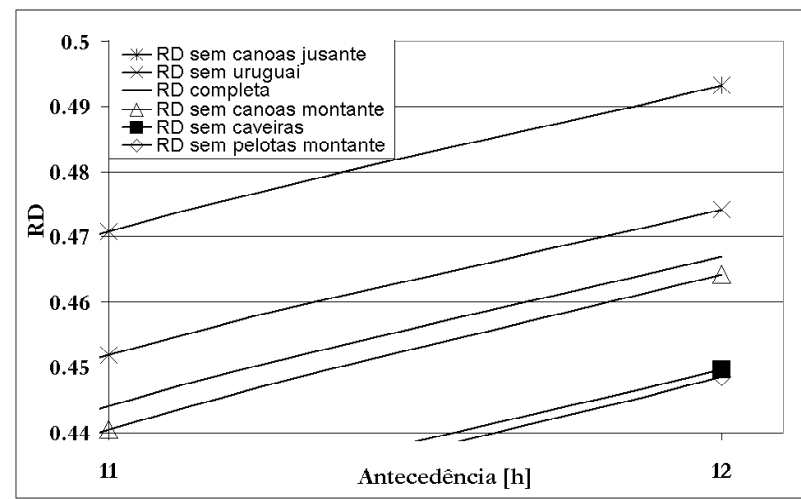

Figura 8 - Detalhe do feixe de curvas RD da figura 7.

Analisando as demais curvas observam-se duas delas que se destacam, caracterizando as regiões de maior importância a serem monitoradas para previsão de vazão em Machadinho: região do Pelotas jusante e região do Inhandava. Ambas as regiões se localizam na parte sul da bacia. Ainda, considerando a terceira curva de maior importância, observa-se que esta também se localiza na região sul (Pelotas montante). Conclui-se, pela análise, que a região sul da bacia é a região de maior importância para geração de escoamento em Machadinho. Uma explicação para este fato é que a região sul da bacia é caracterizada por solos de pouca profundidade, subsolo basáltico e declividades altas. Esses fatores contribuem para maior geração de escoamento superficial e geração de hidrogramas mais rápidos. De fato, comparando as vazões de pico no maior evento do período analisado (2001-2003) que aconteceram entre setembro e outubro de 2001, para o posto Passo do Socorro (bacia do Pelotas - região sul e área de drenagem de $8.400 \mathrm{~km}^{2}$ ) e Passo Caru (bacia do Canoas - região norte e área de drenagem de $10.258 \mathrm{~km}^{2}$ ), nota-se um pico no Passo do Socorro praticamente 2 vezes superior que no Passo do Caru. Apesar da bacia do Passo da Caru ter área de drenagem superior a do Passo do Socorro, as características hidrológicas daquela bacia ocasionam menor geração de escoamento superficial e uma maior regularização da vazão. Também deve-se considerar que, em alguns eventos importantes deste período, as chuvas foram mais intensas na região sul da bacia, inclusive no maior evento do período. Talvez se considerássemos um período maior de dados a tendência observada nas curvas apresentadas não fosse verificada.

Além disso, observa-se que, à exceção da curva "RD sem Uruguai", as demais curvas não se 
cruzam. Esse fato salienta a importância das regiões independente da antecedência, porém, a importância não se mantém constante ao longo da antecedência. O fato da curva "RD sem Uruguai" cruzar com uma das curvas em antecedências baixas, ou seja, alterar a posição de importância, é esperado, uma vez que a região do Uruguai se constitui na região mais próxima ao reservatório de Machadinho. Assim, a contribuição dessa região, é importante para horizontes da ordem do tempo de concentração dessa sub-bacia. Em horizontes maiores, a importância diminui, pois as magnitudes das vazões das outras sub-bacias que chegam ao reservatório preponderam. Era esperado que esta curva cruzasse também as demais, porém isso deve ocorrer para horizontes muitos baixos. Nesses casos o fator RD é negativo mostrando que a previsão por persistência é melhor e não está representado na figura.

Um fato não esperado é das previsões considerando todos os postos na bacia (RD completa). Esperava-se que esta curva ficasse na região como contorno superior às demais, porém considerando todos os postos tem-se uma previsão em Machadinho pior do que a retirada separadamente dos postos da região do Uruguai e Canoas montante. Esse fato pode ter ocorrido por dois fatores: erros nas medições de chuva nos postos dessa região ou pouca sensibilidade do modelo hidrológico a esses postos. Essa última causa é aceitável haja vista que as três curvas (sem Uruguai, sem Canoas montante e completa) se mantém muito próximas. É importante notar que nas regiões do Uruguai e Canoas montante existe uma maior concentração de pluviógrafos, é possível que existam erros associados aos sensores desses equipamentos.

A figura 9 apresenta a estatística do erro padrão da vazão em função da antecedência. Na figura apresentam-se apenas as curvas "sem pluviômetros", "completa" e "persistência". A curva "persistência" considera o erro resultante da persistência, a qual se constitui em utilizar a vazão no instante zero para cada antecedência futura. Observa-se que a curva "persistência" cruza a curva "completa" na antecedência de 5 horas, ou seja, considerando todos os postos na bacia, só se obtém ganhos, com o modelo de previsão de vazão proposto, em termos médios, somente para antecedências acima de 5 horas. $\mathrm{Na}$ análise anterior quando considerou-se a estatística $\mathrm{RD}$, observou-se que a antecedência mínima de previsão para se obter ganhos, ficou em $4 \mathrm{~h}$, porém, seria desconsiderando os postos da região do Uruguai.

A curva "persistência" cruza também a curva "sem pluviômetros", porém, na antecedência próxima de 8 h, ou seja, quando não são considerados os pluviômetros na previsão, obtém-se ganhos fazendo previsão com o modelo hidrológico proposto somente a partir de $8 \mathrm{~h}$ de antecedência.

Conclui-se, dessa forma, que para a situação atual de previsão (somente os pluviógrafos na bacia) só se obtém ganhos em fazer a previsão quando o horizonte for próximo de 8 horas. Caso os pluviômetros fossem substituídos por pluviógrafos e telemetria o ganho ao realizar a previsão passaria para menos de 5 horas, porém, espera-se que o ganho seja ainda maior em termos de antecedência e em termos de eficiência, pois a distribuição temporal da chuva estaria melhor caracterizada.

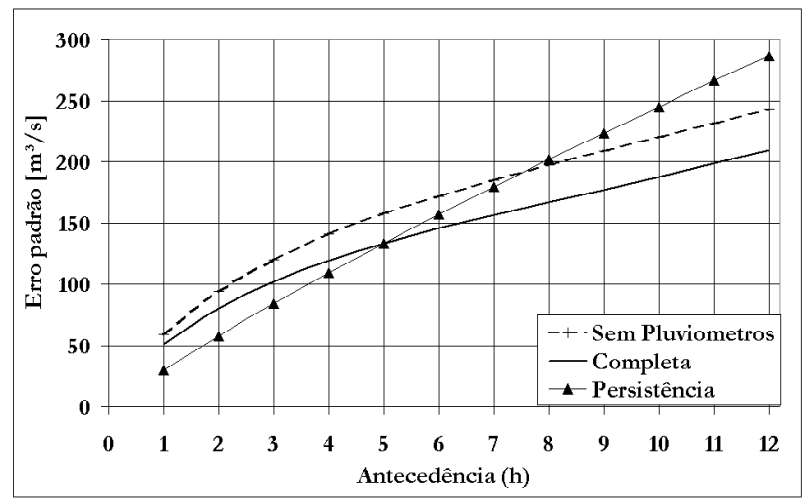

Figura 9 - Erro padrão na vazão em função da antecedência.

Por outro lado, considerando a escassez de recursos para planejar e executar uma rede hidrológica próxima à ideal pode ser inviável tal rede sobre este aspecto. Assim, num período de recursos limitados, poder-se-ia monitorar regiões que influenciam mais nas vazões em Machadinho que seriam as regiões localizadas na parte Sul da bacia (Pelotas jusante, Pelotas montante, e Inhandava) e, inclusive, transferir, para estas regiões, parte dos postos telemétricos da região do Uruguai e Canoas jusante.

\section{Retirada de postos semi-aleatória}

Para este cenário a análise foi feita com base na estatística do erro padrão (equação 2). A figura 10 apresenta os resultados obtidos das previsões para o horizonte de 12 horas com chuva zero. Cada valor das curvas representadas pela figura 10 foi obtido a partir de 4 valores. Esses valores foram originados de previsões do período 11/09/2001 a 29/07/2003 e gerados pela equação 2 (erro padrão médio).

Na legenda da figura 10, a máxima repre- 
senta o máximo dos 4 valores, a mínimo representa o mínimo dos 4 valores e a média representa a média dos 4 valores. Cada ponto do gráfico é resultado de uma previsão para o período.

Observa-se que as curvas apresentam comportamento de natureza exponencial, ou seja, o decréscimo do erro é maior quando poucos postos estão em operação e alguns postos são acrescentados. Considerando que todos os pluviômetros existentes na bacia fossem substituídos por pluviógrafos e incluídos na telemetria, o ganho em termos de redução de erro padrão seria da ordem de $15 \%$. Este ganho pode ser maior, pois seriam reduzidas as incertezas na distribuição temporal da chuva.

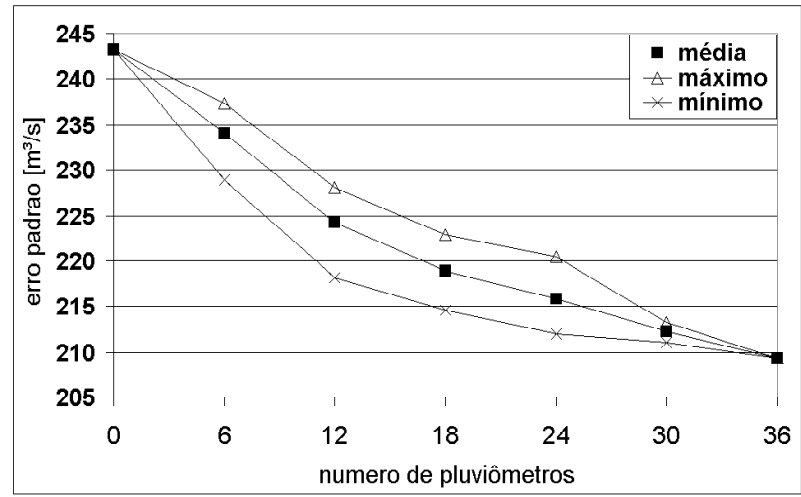

Figura 10 - Erro padrão na vazão em função do número de postos convencionais na bacia.

\section{CONCLUSÕES E RECOMENDAÇÕES}

Os resultados apresentados mostram a importância de uma rede densa de pluviógrafos associada à telemetria para previsão em tempo real quando considerada a precipitação. Por exemplo, quando são retirados todos os pluviômetros na bacia (postos de leitura convencional), há grande perda de desempenho na previsão justificando a substituição desses postos por postos telemétricos. A análise por região salientou a região Sul da bacia como a região de maior importância para previsão de cheias em Machadinho. Se houvesse disponibilidade de recursos financeiros para instalar mais um posto, pela análise proposta é possível concluir que a subbacia do Pelotas jusante deveria receber o posto. $\mathrm{Na}$ análise feita considerando a retirada de postos semialeatória na bacia e considerando a totalidade de postos (pluviômetros mais pluviógrafos) a redução do erro padrão na vazão prevista em Machadinho no horizonte de 12 horas ficaria em torno de $15 \%$.

É importante ressaltar que este estudo foi feito utilizando um período curto de dados - aproximadamente 2 anos. Estudos análogos em outras bacias com períodos maiores de dados podem confirmar os resultados obtidos neste estudo.

Finalmente, um aspecto importante, que não foi abordado nesse estudo, é o custo operacional de ampliar a rede de postos. Confrontar os benefícios em termos de redução do erro na previsão da vazão, na implantação de uma rede de postos mais densa, com os seus custos operacionais é necessária para justificar a necessidade da ampliação.

\section{AGRADECIMENTOS}

Agradecemos a CAPES pelo aporte financeiro concedido ao primeiro autor.

Agradecemos a Vanderleia Schmitz do CLIMER-SC e José Vicente Miranda da Tractebel Energia pela disponibilização dos dados climáticos e hidrológicos.

Agradecemos a Tractebel Energia e ANEEL pelo aporte financeiro concedido através do programa $\mathrm{P} \& \mathrm{D}$.

\section{REFERÊNCIAS}

ANDREOLLI, I. Previsão de Vazão em Tempo Real no Rio Uruguai com Base na Previsão Meteorológica. Porto Alegre: UFRGS. Dissertação (Mestrado em Recursos Hídricos e Saneamento Ambiental), Instituto de Pesquisa Hidráulicas, Universidade Federal do Rio Grande do Sul, 2003.

CLARKE, R. T; DIAS, P. L. S. As necessidades de observação e monitoramento dos ambientes brasileiros quanto aos recursos hídricos. Secretaria Técnica do Fundo Setorial de Recursos Hídricos, Centro de Gestão e Estudos Estratégicos Ciência, Tecnologia e Inovação. Disponível em: $<$ http://www.finep.gov.br/ fundos_setoriais /ct_hidro/documentos/ct-hidro01obs_ e_monit_ amb_rh.pdf>. Nov, 2002.

COLLISCHONN, W. Simulação Hidrológica de Grandes Bacias. Porto Alegre: UFRGS. Tese (Doutorado em Recursos Hídricos e Saneamento Ambiental), Instituto de Pesquisa Hidráulicas, Universidade Federal do Rio Grande do Sul, 2001.

COLLISCHONN, W; HAAS, R; ANDREOLLI, I; TUCCI, 
C. E. M. Flow forecasts for river Uruguay using rainfall forecasts by a regional weather prediction model. Submitted Journal of hydrology, mar. 2004.

KITANIDIS, P. K. AND BRAS, R. L. Real time forecasting with a conceptual hydrologic model 2: Applications and results. Water Resources Research, Vol. 16 No. 6 pp. 1034-1044, 1980.

LETTENMAIER, D. P; WOOD, E. F. Hydrologic Forecasting. In: David R. Maidment. Handbook of Hydrology, ed. 1993, Editora: McGRAW - Hill.

NASH, J. E; SUTCLIFFE, J. V. River flow forecasting through conceptual models. Part I a Discussion of Principles. Journal of Hydrologic, n.1, v. 10, p. $282-290,1970$.

O'CONNELL, P. E; CLARKE, R. T. Adaptive hydrological forecasting - a review. Hydrological Sciences Bulletin - des Sciences Hydrologiques, v. 26, n. 2, p. 175-205, jun. 1981.

TUCCI, C. E. M; CLARKE, R. T; DIAS, P. L. S. da; COLLISCHONN, W. Previsão de Vazão com Base na Previsão Climática. Distrito Federal: Dupligráfica. Projeto BRA/00/029, capacitação do setor elétrico brasileiro em relação à mudança global do clima. Relatório de pesquisa, 2003.

TUCCI C. E. M; CLARKE, R. T. Adaptive forecasting with a conceptual rainfall-runoff model. IAHS. p. 455454, 1980.

TUCCI, C. E. M; COLLISCHONN, W; ANDREOLLI, I. Previsão de Vazões de Curto e Médio Prazo na Operação de Usinas Hidrelétricas. Porto Alegre: UFRGS. Instituto de Pesquisa Hidráulicas, Universidade Federal do Rio Grande do Sul. Relatório Técnico, P\&D e ANEEL, 2003.

WOOD, E. F; O'CONNELL, E.. Real-time forecasting. In Anderson, M. G; Burt, T. P. Hydrological Forecasting, ed 1985. John Wiley \& Sons, New York.

\section{Analysis of the Rainfall Gauging Network for Real Time Forecasting in the Uruguay River Basin}

\section{ABSTRACT}

In real time forecasting hydrologic and meteorological models are used to forecast the outflow in future times. These forecasts depend on knowledge of the state of the system as streamflow observed at upstream points in the river and observed or forecast rainfall. Rainfall estimates are obtained from a network of telemetric gauges distributed in the basin and are useful for forecasts in future times up to the basin concentration time. Analysis of the raingauge distribution in the basin may help size the necessary gauge network. This paper presents an evaluation of a rainfall gauging network based on results of real time streamflow forecasts. The analysis was performed in the Uruguay river Basin upstream from the Machadinho reservoir, (32,000 $\mathrm{km}^{2}$ ). More than two years of continuous forecasts have been evaluated considering various scenarios of available rainfall gauges and their distribution in the basin. Results for this basin show that improvements in the rainfallgauging network may provide significant benefits in terms of flow forecasting, reducing forecast errors.

Key words: rainfall gauging; real time forecasting; Uruguay river 